\title{
VISUALISASI OPERASI ABWR MENGGUNAKAN SOFTWARE DCS CENTUM VP BERBASIS DATA SIMULATOR ABWR IAEA
}

\author{
Julfa Muhammad Amda ${ }^{*}$, Djiwo Harsono ${ }^{1}$, Sutanto ${ }^{1}$ \\ 1) Sekolah Tinggi Teknologi Nuklir, Yogyakarta, Indonesia \\ *Corresponding author: julfamuhammadamda@gmail.com
}

\begin{abstract}
ABSTRAK
VISUALISASI OPERASI ABWR MENGGUNAKAN DCS CENTUM VP BERBASIS DATA SIMULATOR ABWR IAEA. Visualisasi operasi ABWR yang dibuat adalah visualisasi dari beberapa parameter pada ABWR menggunakan perangkat lunak DCS CENTUM VP. Parameter yang dikendalikan adalah Rod Position yang mempengaruhi parameter-parameter Dome Steam Temperature, Steam Flow from Core, Thermal Power, Average Fuel Temperature, Coolant Flowrate, Coolant Temperature, Coolant Quality, Turbine Governor Valve, Generator Power, Feedwater Flowrate, and Feedwater Temperature. Simulasi ini dibuat berdasarkan data yang diambil dari IAEA Simulator ABWR. Data yang dihasilkan kemudian diproses untuk mendapatkan persamaan matematisnya. Perancangan visualisasi dilakukan menggunakan DCS CENTUM VP, dengan membuat tampilan simulasi pada Human Interface Station (HIS) dan program pada Field Control System (FCS).
\end{abstract}

Kata kunci: ABWR, Simulator ABWR IAEA, DCS CENTUM VP, HIS, FCS.

\begin{abstract}
OPERATION VISUALIZATION OF ADVANCED BOILING WATER REACTOR (ABWR) USING DISTRIBUTED CONTROL SYSTEM (DCS) CENTUM VP SOFTWARE BASED ON THE DATA OF IAEA ABWR SIMULATOR. Operating visualization of Advanced Boiling Water Reactor $(A B W R)$ that have been made is visualization of some parameters on the ABWR. The parameters to be controlled is Rod Position that will affect parameters Temperature Steam Dome, Dome Pressure, Steam Flow from Core, Thermal Power, Average Fuel Temperature, Coolant flowrate, Coolant Pressure, Coolant Temperature, Coolant Quality, Reactor Pressure Valve, Turbine Governor Valve, Power Generator, Feedwater flowrate, and Feedwater Temperature. This simulation is based on data taken from IAEA Simulator ABWR. The datas from simulator processed to get equation mathematics. The design of the simulation is done using DCS CENTUM VP, by making display the simulation on the Human Interface Station (HIS) and the program on Field Control System (FCS).
\end{abstract}

Key words: ABWR, IAEA ABWR Simulator, DCS CENTUM VP, HIS, FCS

\section{PENDAHULUAN}

\section{Latar Belakang}

Kebutuhan energi listrik dari tahun ke tahun terus meningkat seiring dengan perkembangan pola hidup masyarakat, dari sektor rumah tangga sampai sektor industri. Untuk memenuhi permintaan energi listrik yang terus meningkat, Pembangkit Listrik Tenaga Nuklir (PLTN) merupakan solusi sumber energi listrik yang menjanjikan. Untuk meningkatkan kepercayaan dan diterimanya kehadiran PLTN oleh masyarakat dunia, maka telah dikembangkan desain PLTN mutakhir seperti jenis ABWR yang merupakan tipe modifikasi dari BWR.

ABWR merupakan proyek reaktor berteknologi maju dan berukuran besar yang pertama diimplementasikan pada pembangunan Reaktor Kashiwazaki-Kariwa unit 6 dan 7 di Jepang dan dioperasikan pada tahun 1996 dan 1997. Reaktor ini adalah reaktor jenis ABWR (1356 MWe). Seluruh sistem reaktor ABWR ini mengalami peningkatan teknologi dan prosedur operasional, kinerja dan burn up yang lebih baik, interface manusia-mesin dengan 
komputer dan peningkatan latihan dengan simulator. Reaktor ini merupakan PLTN mutakhir dan modern pertama di dunia yang mempunyai kapasitas listrik netto yang tertinggi. Reaktor ABWR ini menggunakan sistem resirkulasi dengan pompa internal, mekanisme penggerakan batang kendali yang baik, tiga sistem pendinginan darurat, dan bejana pengungkung beton. Dengan desain ini diperoleh faktor ketersediaan yang meningkat, keselamatan yang lebih tinggi, reaktor yang lebih kompak dan mudah digunakan, dan sistem turbin yang efisien [1].

Penggunaan sistem kendali dalam industri disebabkan karena plant yang semakin kompleks dan memerlukan ketelitian yang tinggi. Perangkat pengendalian telah berkembang dari manual, Pneumatic Analog, Electric Analog, Centralized Computer Control System, Programmable Logic Controller (PLC) hingga Distributed Control System (DCS).

DCS adalah sebuah istilah yang sangat luas yang menggambarkan sebuah solusi untuk industri yang sangat variatif. Secara garis besar DCS terdiri dari Control System, Control Network, dan Field Instrument. DCS dapat diaplikasikan sebagai sistem kendali di industri Chemical, Food and Beverage, Iron and Stell, LNG Supply Chain, Petrochemical, Oil and Gas, Petrochemical, Pharmaceutical, Power, Pulp and Paper, Refining, Water and Wastewater [2]

Penelitian sebelumnya tentang Boiling Water Reactor with Passive Safety Systems, telah dibuat simulator PLTN jenis ABWR berbasis PC dengan menggunakan software Labview, melalui simulator tersebut dapat diketahui karakteristik operasional ABWR sehingga mempermudah untuk memahami parameter-parameter yang dikendalikan pada ABWR, pada penelitian tersebut dioperasikan tanpa terhubung ke field instrument, namun tetap mewakili kondisi aktual di lapangan [1].

Berdasarkan uraian sebelumnya, sistem kendali pada ABWR dapat dirancang menggunakan DCS dan dapat dihubungkan dengan field instrument. Pada penelitian ini dibuat simulasi pengendalian operasi ABWR berbasis software DCS CENTUM VP. Sehingga diharapkan dari hasil penelitian ini, dapat menambah wawasan dan praktek dalam operasional PLTN jenis ABWR dengan menggunakan DCS CENTUM VP sebagai media pembelajaran.

\section{DASAR TEORI}

\section{Simulasi}

Simulasi merupakan suatu teknik meniru operasi-operasi atau proses- proses yang terjadi dalam suatu sistem dengan bantuan perangkat komputer dan dilandasi oleh beberapa asumsi tertentu sehingga sistem tersebut bisa dipelajari secara ilmiah [3].

Dalam simulasi digunakan komputer untuk mempelajari sistem secara numerik, dimana dilakukan pengumpulan data untuk melakukan estimasi statistik untuk mendapatkan karakteristik asli dari sistem. Simulasi merupakan alat yang tepat untuk digunakan terutama jika diharuskan untuk melakukan eksperimen dalam rangka mencari komentar terbaik dari komponen-komponen sistem. Hal ini dikarenakan sangat mahal dan memerlukan waktu yang lama jika eksperimen dicoba secara riil. Dengan melakukan studi simulasi maka dalam waktu singkat dapat ditentukan keputusan yang tepat serta dengan biaya yang tidak terlalu besar karena semuanya cukup dilakukan dengan komputer.

Pendekatan simulasi diawali dengan pembangunan model sistem nyata. Model tersebut harus dapat menunjukkan bagaimana berbagai komponen dalam sistem saling berinteraksi sehingga benar-benar menggambarkan perilaku sistem. Setelah model dibuat maka model tersebut ditransformasikan ke dalam program komputer sehingga memungkinkan untuk disimulasikan.

\section{Advanced Boiling Water Reactor (ABWR)}

Reaktor ABWR merupakan reaktor daya pembangkit listrik tenaga nuklir yang menggunakan air ringan sebagai pendingin maupun moderatornya. Pada reaktor daya yang dimanfaatkan adalah uap panas bersuhu dan bertekanan tinggi yang dihasilkan oleh reaksi fisi untuk memutar turbin, sedangkan neutron cepat dihasilkan diubah menjadi neutron lambat untuk berlangsungnya reaksi berantai dan sebagian lagi tidak dimanfaatkan. Reaksi fisi berantai hanya terjadi apabila neutron termal atau lambat mampu menembak Uranium-235 yang lainnya hingga terjadilah reaksi berantai secara terus menerus. Cara mengubah neutron yang berkecepatan tinggi 
menjadi neutron berkecepatan rendah (neutron lambat) adalah dengan menumbukkannya pada inti atom hidrogen dalam air. Jadi air di dalam kolam reaktor ini berfungsi sebagai pemerlambat (moderator), sebagai pendingin dan juga sebagai perisai radiasi. Beberapa bahan pada umumnya yang dipergunakan sebagai bahan pendingin reaktor nuklir adalah air ringan [1].

Untuk diagram Advanced Boiling Water Reactor ditunjukkan pada Gambar 1.

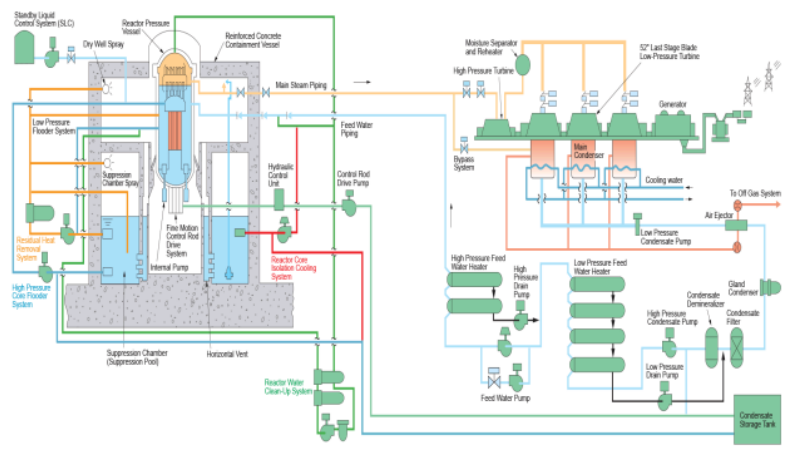

Gambar 1 Advanced Boiling Water Reactor

(ABWR) Diagram [1]

\section{Sistem Kendali}

Sistem kendali adalah sistem dimana suatu masukan atau beberapa masukan digunakan untuk mengontrol suatu keluaran pada nilai tertentu, memberikan urutan kejadian tertentu, atau memunculkan suatu kejadian jika beberapa kondisi tertentu terpenuhi.

Dalam industri modern, penggunaan sistem otomasi terus menerus mengalami peningkatan. Ada kalanya proses kini tidak memerlukan tenaga manusia sehingga kendali otomasi terhadap mesin sekarang menjadi bagian yang vital. Keuntungan dari kendali semacam ini mencakup konsistensi produk yang lebih baik, berkurangnya biaya produksi dan tingkat keamanan dan keselamatan yang lebih tinggi. [4].

Ada dua jenis sistem kendali, yaitu sistem kendali loop terbuka dan sistem kendali loop tertutup. Sistem kendali loop terbuka adalah sistem kendali yang keluarannya tidak berpengaruh terhadap aksi keluaran selanjutnya. Atau dengan kata lain, sistem ini tidak memiliki umpan balik. Sedangkan sistem kendali loop tertutup merupakan sistem kendali yang keluarannya berpengaruh terhadap aksi keluaran selanjutnya. Berbeda dengan loop terbuka, sistem loop tertutup memiliki feed back, seingga keluarannya bisa dijadikan perbandingan umpan balik dan masukan untuk menentukan aksi keluaran berikutnya. Gambar 2 berikut erupakan skema dasar dari sistem kendali loop tertutup dan terbuka.

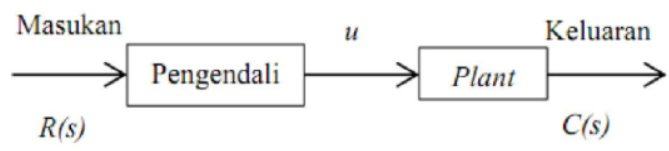

(a)

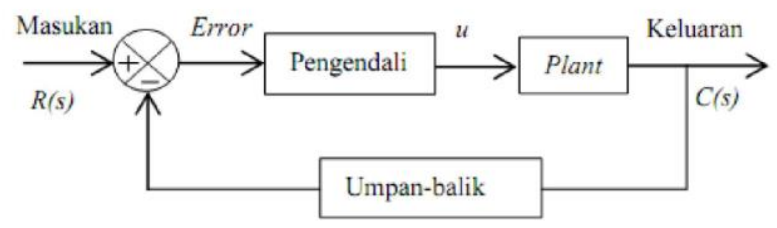

(b)

Gambar 2 (a) Sistem kendali loop terbuka (b) Sistem kendali loop tertutup

\section{Distributed Control System (DCS)}

Distributed Control System (DCS) merupakan suatu sistem yang mendistribusikan berbagai fungsi yang digunakan untuk mengendalikan berbagai variabel proses dan unit operasi proses menjadi suatu pengendalian yang terpusat pada suatu control room dengan berbagai fungsi pengendalian, monitoring dan optimasi. Sistem kendali terdistribusi banyak diaplikasikan pada suatu proses industri yang mempunyai karakteristik berupa proses yang kontinu atau batch. Pada proses kontinu, besaran atau parameter kendali bersifat data yang secara terus menerus mengalami perubahan seiring dengan perubahan parameter kendalinya. Contoh dari proses kontinu di industri adalah pada industri pembangkitan energi listrik. Industri pembangkit tenaga listrik beroperasi secara terus menerus sepanjang waktu. Karena proses berlangsung secara terus menerus maka diperlukan sistem kendali proses yang baik sepanjang waktu. Industri semacam ini sangat bergantung pada keandalan proses produksinya untuk menjamin kualitas produk dan jasanya. Parameter-parameter kendali 
seperti pada PLTN kecepatan aliran air, level air, tekanan pada tabung, temperatur ruang dan parameter lainnya harus terkendali sepanjang waktu.untuk itu dibutuhkan sistem kendali yang mampu bekerja secara kontinu dengan tingkat keandalan yang tinggi.

Untuk arsitektur DCS Yokogawa dapat dilihat pada Gambar 3.

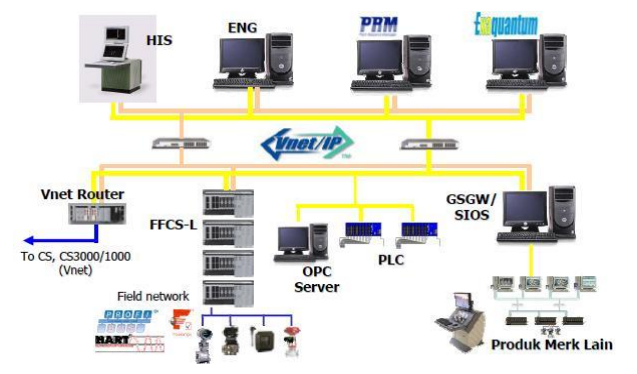

Gambar 3 Arsitektur DCS Yokogawa

Pada Gambar 3, FCS (Field Control Station) terhubung dengan transmitter, control valve serta alat instrumentasi yang lain yang berfungsi sebagai kendali proses yang digunakan untuk mengendalikan variable proses yang akan dikendalikan, GSGW/SIOS digunakan sebagai penghubung antara DCS Yokogawa dengan DCS lain di luar dari sistem DCS Yokogawa untuk dapat saling berkomunikasi baik dalam kendali data dan komunikasi data, OPC server juga digunakan untuk menghubungkan DCS dengan sistem lain di luar di DCS Yokogawa tetapi hanya dalam level software untuk dapat berkomunikasi satu sama lain misalnya: PLC Siemens ingin dihubungkan dengan DCS Yokogawa dan Software SCADA (Supervisory Control And Data Acquisition).

HIS (Human Interface System) merupakan tampilan visual dari parameterparameter dari pabrik yang ingin dikendalikan dalam sebuah layar monitor, sedangkan EWS (Engineering Work Station) sebuah personal komputer berfungsi untuk monitoring, operation, dan engineering sehingga dapat memodifikasi, memperbaiki, atau menambahkan program baik berupa logic, sequential, graphic builder, atau yang lain.

Pada DCS Yokogawa, jenis network atau jaringan yang digunakan adalah teknologi Vnet/IP dengan topologi star. Dari gambar di atas, dapat diketahui bahwa garis kuning merupakan representasi jalur data komunikasi dan garis coklat merepresentasikan jalur data kendali.

\section{Function Block pada Distributed Control System Yokogawa}

Function block dalam DCS digunakan untuk membuat program dalam FCS. Terdapat 3 jenis Function block yang digunakan dalam penelitian yaitu manual loader block (MLD), general purpose calculation block (CALCU) dan proportional, integral, and derivative control (PID-Control).

MLD merupakan function block yang berfungsi untuk menghasilkan keluaran. Keluaran MLD dapat digunakan untuk mengoperasikan final control element atau hanya sebagai penampil data. Keluaran MLD disebut sebagai MV (manipulated value) ini dapat diatur secara manual melalui HIS atau secara otomatis melalui pemrograman.

CALCU adalah function block yang berfungsi mengeksekusi logika dan kalkulasi matematika. Input pada CALCU terdiri dari IN dan Q01...Q07 yang disebut sebagai RV dan RV1...RV7. sedangkan outputnya adalah OUT yang disebut sebagai CPV dan J01...J03 yang disebut sebagai CPV1..CPV3.

Contoh eksekusi logika yang dilakukan oleh function block CALCU adalah program pengkondisian seperti IF...THEN. Program CALCU mempunyai batasan baris program yaitu maksimal berisi 20 baris.

\section{Simulator ABWR IAEA}

International Atomic Energy Agency (IAEA) telah membuat program untuk mensimulasikan ABWR berbasis PC.

Tujuan dari pembuatan simulator ini adalah untuk memberikan wawasan dan praktek dalam operasional ABWR. Program ini juga dapat digunakan sebagai bahan pelatihan untuk mengoperasikan ABWR. Peserta pelatihan dapat mempraktekkan dan memahami karakteristik dari PLTN ABWR.

Simulator dapat dijalankan PC dengan memiliki spesifikasi minimal: kecepatan CPU 1,7 GHz, $512 \mathrm{Mb}$ RAM, $30 \mathrm{~Gb}$ Harddrive, RAM $32 \mathrm{Mb}$ tampilan Adaptor, resolusi video 1024x768, 12 inchi atau lebih dengan resolusi monitor warna tinggi SVGA, keyboard dan mouse, widows 2000 atau XP.

Parameter-parameter yang ditampilkan adalah: tekanan di kubah, suhu uap kubah, aliran uap inti, level air reaktor, tingkat daya neutron, aliran pendingin, suhu bahan bakar, 
posisi batang kendali, keluaran generator, total aliran feedwater, dan suhu feedwater.

\section{METODE PENELITIAN}

\section{Pengambilan Data Parameter-Parameter ABWR}

Data karakteristik ABWR diambil dari simulator yang telah dibuat oleh International Atomic Energy Agency (IAEA). Simulator dapat dijalankan minimal memiliki spesifikasi kecepatan CPU 1,7 GHz, $512 \mathrm{Mb}$ RAM, $30 \mathrm{~Gb}$ Harddrive, RAM $32 \mathrm{Mb}$ tampilan Adaptor, resolusi video $1024 \times 768,12$ inchi atau lebih dengan resolusi monitor warna tinggi SVGA, keyboard dan mouse, widows 2000 atau XP.

\section{Pengolahan Data Parameter-Parameter ABWR}

Dari data hasil operasi reaktor ABWR pada tiap tingkat daya, dapat dibuat hubungan perubahan batang kendali dengan parameterparameter lainnya yang terdapat pada reaktor ABWR. Setelah didapatkan data-data kendali pada simulator, kemudian dilakukan interpolasi polinomial, yaitu sebuah metode untuk menaksir (mengestimasi) nilai di antara titiktitik data yang tepat. Persamaan polinomial adalah persamaan aljabar yang hanya mengandung jumlah dari variabel $x$ berpangkat bilangan bulat (integer). Bentuk umum persamaan polinomial order $n$ adalah:

$$
f(x)=a_{0}+a_{1} x+a_{2} x^{2}+\ldots+a_{\mathrm{n}} x^{\mathrm{n}}
$$

dengan $a_{0}, a_{1}, a_{2}, \ldots, a_{\mathrm{n}}$ adalah parameter yang akan dicari berdasarkan titik data, $n$ adalah derajat (order) dari persamaan polinomial, dan $x$ adalah variabel bebas. Untuk $(n+1)$ titik data, hanya terdapat satu atau kurang polinomial order $n$ yang melalui semua titik.

Adapun persamaan interpolasi yang akan dibuat yaitu hubungan antara Rod Position terhadap parameter-parameter sebagai berikut:

1. Thermal Power

2. Fuel Temperature

3. Coolant Flowrate

4. Coolant Temperature

5. Coolant Quality

6. Steam Flow

7. Governor
8. Generator Power

9. Feedwater Flow, dan

10. Feedwater Temperature.

\section{Pembuatan Visualisasi Sistem Kendali ABWR}

Pembuatan visualisasi pengendalian ABWR menggunakan software CENTUM VP. Adapun pembuatan dilakukan pada Field Control System (FCS) dan Human Interface Station (HIS). FCS dapat dihubungkan dengan transmitter, coltrol valve serta alat instrumentasi lain yang akan dikendalikan, sedangkan HIS merupakan tampilan visual dari parameter-parameter dari ABWR yang ingin dikendalikan dalam sebuah layar monitor.

Pemrograman pada DCS CENTUM VP memiliki beberapa tahapan agar sistem dapat dijalankan, maka tahapannya harus diikuti dari awal sampai akhir sebagai berikut.

- Mendefinisikan Input/Output yaitu definisikan card $I / O$ yang digunakan baik jenis analog maupun digital

- I/O Labelling yaitu setiap I/O memiliki channel dan pada tahap ini tiap channel diberikan label tertentu sehingga memudahkan dalam pembuatan drawing builder

- Membuat Functional Block \& Logic di Control Drawing Builder. Tahap ini dirancang program untuk proses yang kita buat, pemrogramannya berbasis blok diagram

- Membuat grafik di Graphic Builder atau disebut Human Interface Station (HIS). Dibuat tampilan grafik dari proses kendali yang akan dirancang. Tampilan grafik menampilkan tag komponen seperti valve, motor, controller, trend dan lain-lain.

- Test Function. Dapat dibagi menjadi dua tipe, yaitu virtual test dan target test. Virtual test yaitu dilakukan dengan menggunakan simulator FCS sebagai pengganti FCS yang asli. Sedangkan target test dibagi lagi menjadi I/O disconnected yang berarti menggunakan virtual I/O ketika dijalankan dan menggunakan I/O asli yang dilakukan di pabrik-pabrik untuk menjalankan fungsi sistem kendali. 
Adapun tampilan overview ABWR yang akan dirancang dapat dilihat pada Gambar 4 sebagai berikut:

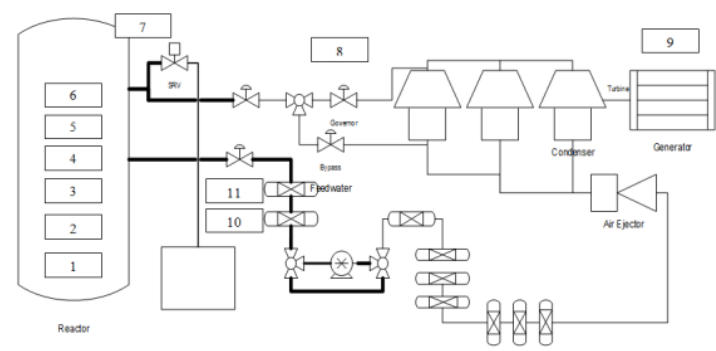

Gambar 4 Desain Overview ABWR

\section{HASIL DAN PEMBAHASAN.}

\section{Hasil Pembuatan Human Interface Station}

Pada penelitian ini, dibuat tiga tampilan Human Interface Station yang berfungsi untuk memonitoring dan mengendalikan proses pada ABWR.

Tampilan pertama dapat dilihat pada Gambar 5 sebagai tampilan Overview ABWR dimana tampilan ini merupakan sistem plant utama. Tidak ada nilai masukan pada tampilan ini, sehingga hanya berfungsi sebagai monitoring. Parameter-parameter yang dapat dilihat pada tampilan ini diantaranya adalah: Rod Position, Dome Steam Temperature, Dome Pressure, Steam Flow from Core, Thermal Power, Average Fuel Temperature, Coolant Flowrate, Coolant Pressure, Coolant Temperature, Coolant Quality, Reactor Pressure Valve, Turbine Governor Valve, Generator Power, Feedwater Flowrate, and Feedwater Temperature.

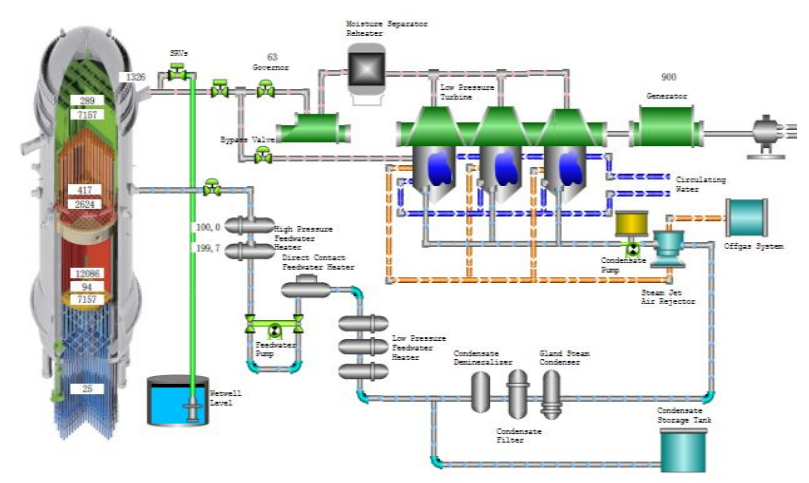

Gambar 5. HIS Advanced Boiling Water Reactor Overview

Tampilan kedua dapat dilihat pada Gambar 6 sebagai tampilan pengendalian pada
ABWR, dengan 8 buah batang kendali yang diasumsikan untuk mewakili jumlah batang kendali pada Real Plant. Pada tampilan ini, pengendalian parameter-parameter yang terdapat pada ABWR menggunakan tombol kendali untuk mengatur posisi batang kendali. Tombol Run-In berfungsi untuk mendorong batang kendali ke dalam teras reaktor, sedangkan tombol Run-Out berfungsi untuk menarik batang kendali keluar dari teras reaktor. Kemudian pada tampilan ini dapat dilihat pengaruh perubahan batang kendali terhadap parameter-parameter yang lainnya.

\section{ADVANCED BOILING WATER REACTOR CONTROL}
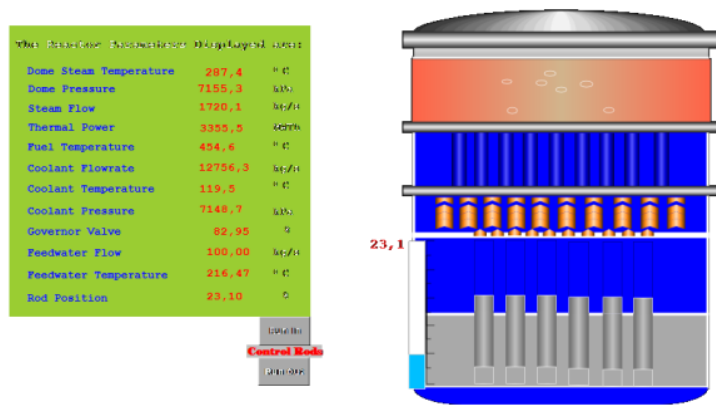

Gambar 6. HIS Advanced Boiling Water Reactor (ABWR) Control

Sehingga untuk tampilan pertama dan kedua merupakan tampilan yang berfungsi untuk mensimulasikan parameter-parameter pada ABWR yang didapatkan dari data operasi pada simulator ABWR IAEA.

Untuk tampilan ketiga dapat dilihat pada Gambar 7. Pada tampilan ini menunjukkan sistem kendali level reaktor, dengan kontrol PID utama yaitu pada level reaktor dengan Tag Name LIC001 dan kontrol Cascade pada aliran feedwater dengan Tag Name FIC001.

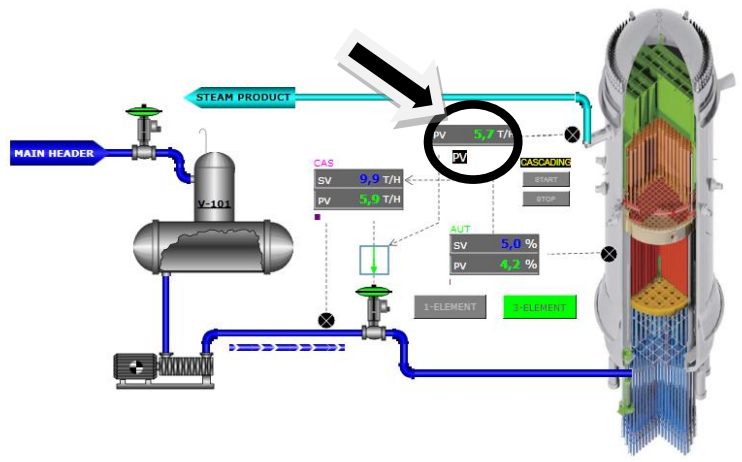

Gambar 7. HIS Water Level Reactor Control System 


\section{Hasil Pengujian Operasi ABWR}

Pengujian yang dilakukan untuk menghasilkan daya yang diharapkan yaitu sebesar 1265 MW. Adapun yang dilakukan adalah menarik batang kendali dari bahan bakar Run-Out, dengan menggunakan tombol kendali posisi batang kendali yang telah tersedia sampai pada posisi $22,10 \%$. Pada display, akan terlihat nilai dari parameterparameter Dome Steam Temperature $286,7{ }^{\circ} \mathrm{C}$, Dome Pressure 7156,2 kPa, Steam Flow from Core 1884,2 kg/s, Thermal Power 3645 MWTh, Average Fuel Temperature $469,6{ }^{\circ} \mathrm{C}$, Coolant Flowrate $12547 \mathrm{~kg} / \mathrm{s}$,Coolant Pressure 7149,6 kPa, Coolant Temperature $132,3{ }^{\circ} \mathrm{C}$, Turbine Governor Valve 91,33\%, Feedwater Flowrate 100 kg/s, Feedwater Temperature $221,49{ }^{\circ} \mathrm{C}$. Hasil yang didapatkan pada Gambar 4.11 juga dapat terbaca pada tampilan Overview ABWR seperti pada Gambar 8.

Dari hasil pengujian, telah dapat dibuat visualisasi pengoperasian reaktor ABWR menggunakan software DCS CENTUM VP berdasarkan data Simulator ABWR IAEA.

\section{KESIMPULAN}

Visualisasi operasi ABWR menggunakan DCS CENTUM VP telah berhasil dilakukan. Pemodelan matematika didapatkan dari pengolahan data operasi SIMULATOR ABWR IAEA, kemudian diolah menggunakan blok Calculation pada perangkat lunak DCS CENTUM VP dan dikoneksikan dengan Human Interface Station, sehingga pembuatan visualisasi operasi ABWR dapat dikendalikan dan dimonitoring.

\section{DAFTAR PUSTAKA}

1. Wagramer. 2009. Boiling Water Reactor with Passive Safety Systems. Austria: International Atomic Energy Agency.

2. Amda, Julfa M. 2014. Operation Project for Training Purposes. Kerja Praktek. STTN-BATAN, Yogyakarta
3. Law, Averill and Kelton, David. 1991. Simulation Modelling and Analysis. London: Mc Graw Hill.

4. Bolton, W. 2006. Sistem Instrumentasi dan Sistem Kontrol. Jakarta: Erlangga.

5. Ogata, Katsuhiko. 1985. Teknik Kontrol Automatik (Sistem Pengaturan). Bandung: Erlangga

6. Reza, Paulus, Hariyanto. 2010. Simulasi Sistem Kontrol Suhu di Reheater pada Boiler di PLTU Paiton Unit 7 dan 8. Tugas Akhir. PEN-ITS Surabaya.

7. Swaminathan. 2008. Modelling of Instrumentation and Control System of Prototype Fast Breeder Reactor. Faculty of Electronics Engineering, Sathyabama University. India.

8. Wijaya, Causa Prima, 2010. Peningkatan DCS dengan Software CENTUM VP pada PT Chevron Geothermal Salak oleh PT Yokogawa Indonesia. Laporan Kerja Praktek. Undip Semarang 